\title{
Raman spectroscopy: A powerful technique for biochemical analysis and diagnosis
}

\author{
Leonardo M. Moreira*, Landulfo Silveira Jr., Fábio V. Santos, Juliana P. Lyon, Rick Rocha, \\ Renato A. Zângaro, Antonio Balbin Villaverde and Marcos T.T. Pacheco \\ Instituto de Pesquisa e Desenvolvimento, Universidade do Vale do Paraíba, São José dos Campos, \\ São Paulo, Brazil
}

\begin{abstract}
The present work focuses on the recent applications of Raman spectroscopy (RS) on biochemical analysis and diagnosis of several biological materials with or without pathological alterations. Important published works about Raman spectroscopy and its use for medical applications were critically reviewed, including articles form our group in order to evaluate the state of the art of the subject. The potential for sample characterization with RS associated to the possibility of analysis in situ makes this instrumental technique in a very auspicious tool of biochemical analysis. RS can promote a significant improvement in the chemical identification and characterization of biological systems, clinical diagnosis and prognosis regarding several diseases and quality of life of innumerous patients. The spectroscopic evaluation is based on the analysis of the Raman spectrum regarding the identification of fingerprint bands of main biological macromolecules, such as nucleic acids, proteins and fat, present in the tissue structure. This review evaluates the employment of RS in diagnosing such pathological manifestations as well as the efforts focused on the instrumental development to biomedical applications. Furthermore, advantages and limitations of this kind of approach are discussed in order to improve the biochemical analysis and diagnosis of several diseases.
\end{abstract}

Keywords: Biochemical analysis, biological fluids, diagnosis, Raman spectroscopy

\section{Introduction}

The clinical process to assess pathological changes in tissue is currently related to the histopathology. However, the management of biopsy material and the interpretation of the respective analysis are not trivial. The clinical characterization based on these analyses could lead to diagnostic delay and to the possibility of taking an unrepresentative sample. Furthermore, this clinical procedure presents high cost and provokes significant patient trauma [1].

Biological samples present significant issues to be addressed, which are associated to their heterogeneous characteristics. Besides, most components are present in low physiological concentration in body fluids (in order of $\mathrm{mmol} / \mathrm{l}$ to $\mathrm{nmol} / \mathrm{l}$ ) [2]. In spite of these difficulties, several spectroscopy techniques have been considered as basis for minimally invasive and non-destructive measuring systems [3]. Among the recent applications of optical spectroscopy in medicine, it can be mentioned, for instance, its employment in gastrointestinal endoscopy, which is likely to be one of the most important areas of impact of this biomedical approach [4,5]. We can mention, for example, the methods based on fluorescence spectroscopy, which also present excellent possibilities in diagnosis [6,7].

\footnotetext{
${ }^{*}$ Corresponding author: Leonardo Marmo Moreira, PhD, Instituto de Pesquisa e Desenvolvimento, Universidade do Vale do Paraíba, Rua Pedro Tursi, 331, 53C, Jardim satélite, CEP 12230090, São José dos Campos, São Paulo, Brazil. E-mail: leonardomarmo@univap.br.
} 
Some techniques of instrumental analysis have been already tested in situ. Indeed, ultraviolet-visible, infrared, fluorescence and Raman spectroscopies have been proposed for biochemical and clinical analysis [8]. These techniques are relatively rapid when compared with conventional clinical methodologies and can be developed for in vivo screening of the disease, thus avoiding the need of a painful biopsy. In this way, these non-invasive techniques can be exploited for population screening, early diagnosis, prognosis, monitoring of therapy and subsequent aspects [9].

In this context, the spectroscopy of molecular vibration has been experiencing a great advancement due to substantial technical improvements in experimental methods, increased computational capabilities and growing analytical demands [10].

The notion that vibrational spectroscopy might play a diagnostic and/or clinical role has emerged through early pioneers who showed that even complex biomolecules such as proteins, lipids, and nucleic acids have distinct vibrational signatures that reflect tissue structure and conformation. Both infrared (FT-IR) and particularly Raman sensitivity have been improved by leaps and bounds, and now there are sampling methods available to measure high quality spectra for virtually any type of biological materials. Considering this, the community of vibrational spectroscopists has taken up the challenge posed by cells, tissues, biological fluids and even intact human beings [11]. Furthermore, vibrational spectroscopies are important analytical references in pharmacy and chemistry allowing several different applications in these areas [12].

Therefore, Raman spectroscopy (RS) has been considered a very promising instrumental technique applied to analyze biological fluids and materials, since this spectroscopy allows a wide biochemical analysis without tissue removal. In this way, this instrumental technique could be employed for several minimally invasive bio-tissue diagnostics [13]. The main advantages of the employment of Raman spectroscopy (RS) over other techniques, such as mass spectroscopy and chromatograpy, is the fact of RS allows the procedure of analysis to be developed in real time, propitiating more precise results with a lower cost, without tissue extraction or use of dyes, labels and other contrast-enhancing agents [14-16]. This information can be obtained therefore in the own microenvironments within intact cells and tissues [15]. Furthermore, RS seems to be very promising because of the wealth of molecular information contained in its spectra [17]. The longer wavelengths used in the newly developed Raman systems reduce the effects of tissue fluorescence, promoting less photolytic degradation of samples, which allows that higher powered laser can be used [18]. In addition to the points mentioned above, it is important to notice that techniques based in the Raman effect require minimal or no sample preparation, minimizing potential artifact generation, which may be introduced by extensive preparative techniques; additionally sample analysis is not destructive [19]. Other fundamental topic is the high sensitivity to small structural changes, which allows a wide analysis of the physico-chemical properties of the biological materials, in spite of the high chemical complexity of these systems [20]. Raman spectroscopy also offers certain distinct advantages over other techniques, which include high spatial resolution (down to $1 \mu \mathrm{m}$ ), use of less harmful NIR radiation and absence of effective influence in the spectrum by water bands and atmospheric contributions, which can be a difficult in FTIR [9,21].

Raman spectroscopy (RS) has been applied to determine the diagnosis of several other diseases, such as skin cancer [22] and atherosclerosis [13]. Pilloto and co-workers [23], for example, identified the presence of lactic acid in human serum and blood from a Wistar rat, in vitro and in vivo, through Near Infrared RS, confirming the possibility of employment of this technique as a noninvasive and effective method of blood diagnosis. Benício and co-workers [24] described an interesting approach focusing on a non-invasive method of real time monitoring of fast processes. This article demonstrates a dynamic evaluation of the photopolymerization of dental resin composite through near infrared Raman spectroscopy 
system. In this work, the intensity of the $1640 \mathrm{~cm}^{-1}$ Raman peak, assigned to the aliphatic carbon double bond of resin, which was chosen to calculate the conversion degree of the resin photopolymerization, obtaining results with excellent resolution. Indeed, the study of techniques based on Raman spectroscopy for deep non-invasive probing of diffusely scattering media such as living tissue and powders, is an emerging area in order to promote several applications, such as quality control of pharmaceutical products [25]. Moreover, new approaches have used Raman spectroscopy in sportive medicine in order to evaluate the production of lactic acid inside of several muscles with auspicious results [26].

Likewise, it has been recently noticed the obtaining of noninvasive Raman spectra of human blood in vivo. This application presents auspicious perspectives to the employment of Raman spectroscopy in advance analysis of biological materials [27]. In fact, the main difficulties of the use of this technique in vivo are associated to the repeatable and quantifiable results, since the occurrence of variability in the pathlength through pliable tissues is common, as well as the variation in the optical properties of those tissues, temperature variability and low resolution as function of the pulsatile nature of blood flow [28]. Furthermore, temperature effects on several biological systems have been studied in vitro using Raman spectroscopy [29].

Thus, the versatility of Raman spectroscopy applied to biochemical analysis and diagnosis is evident and the perspectives of future advancements are auspicious.

\section{Raman scattering effect}

Although the Raman effect was described by C.V. Raman in 1928, the technique did not become a viable medical tool until the 1980s with the introduction of the Fourier transform (FT) Raman instrument $[2,30]$.

The technique consists in an inelastic process that occurs when a sample is illuminated with a monochromatic light source, such as a laser beam. In this process, energy from the incident photons is transferred to the sample molecules, exciting them to high vibrational modes. Scattered photons have a lower frequency than the incident ones due to the energy transfer [14]. Therefore, RS is based on inelastic scattering in which photons incident on sample transfer energy to or from a molecular vibrational mode. In this incoherent two-photon process, the simultaneous absorption of an incident photon is accompanied by the emission of a Raman photon with a shift in wavelength corresponding to the vibrational level energy difference in the molecule [31]. Figure 1 represents the physical process associated to the Raman scattering effect.

Raman scattering effect is inherently weak, typically $10^{-9}$ to $10^{-6}$ of the intensity of the Rayleigh background. For this reason, it is difficult to observe the Raman effect without intense monochromatic excitation and a sensitive detector. These limitations justify the fact that its biological applications have been more divulgated only in the recent decades [32]. Figure 2 represents a simple model of the modern Raman spectroscopy instrument, illustrating the main parts of its optical system. It is important to notice that RS using near-infrared radiation has the advantage that the irradiation penetrates deeper into the biological tissues and the sample fluorescence is lower [14].

The emission lines in the Raman effect are sharp, well resolved, being characteristics of the emitting material. Therefore, Raman spectroscopy is a power tool for identification of bio-analytes. It is important to notice that infrared spectroscopy can also be used in order to evaluate the physico-chemical properties of biological materials, but due to its higher band widths, its analysis is less precise.

Raman spectrum can determine the composition of the sample, since each molecule has its own characteristic Raman spectrum as function of its vibrational modes [14]. In this context, the improvements in 


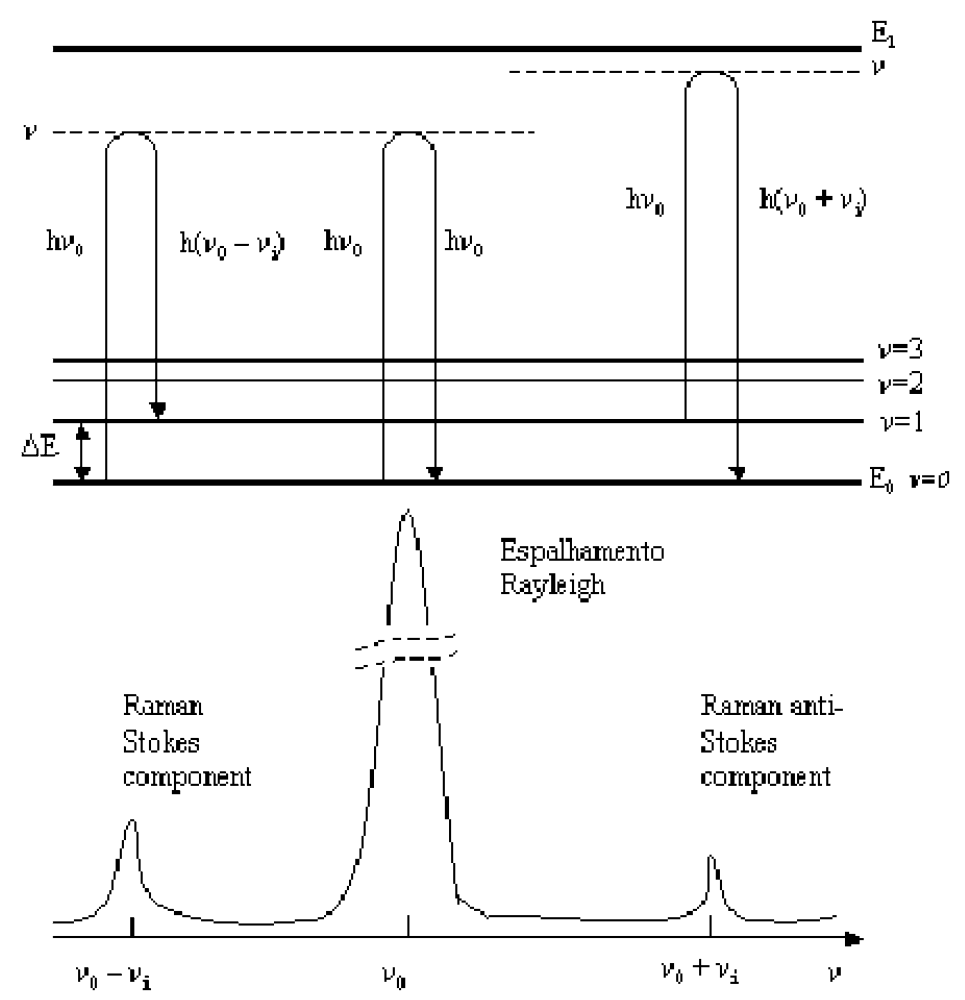

Fig. 1. Schematic representation of the physical process of the Raman scattering effect.

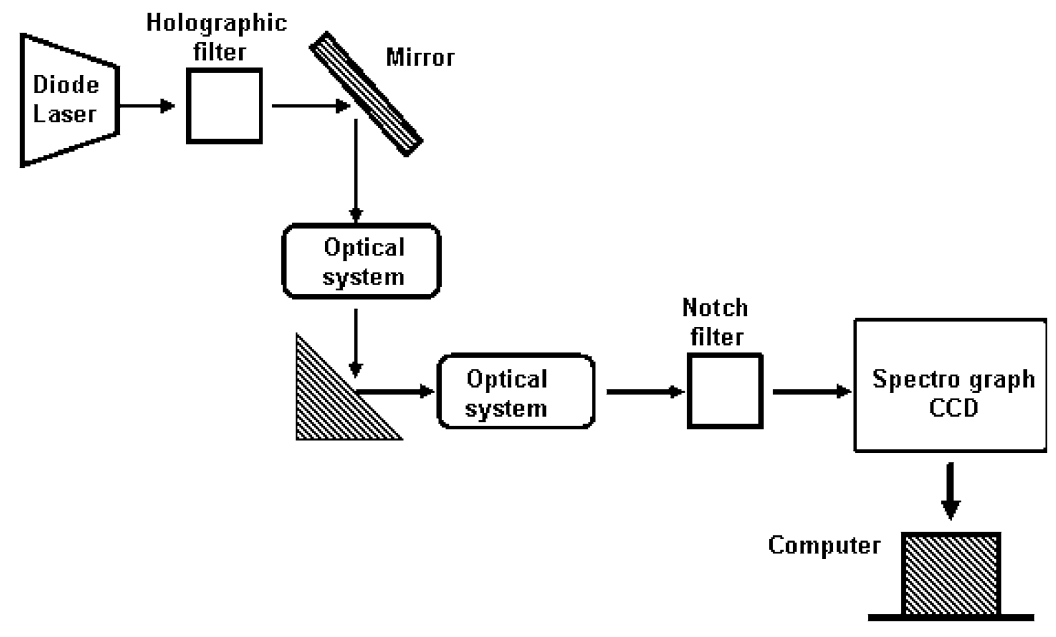

Fig. 2. Schematic of laser Raman instrumentation.

lasers, filters, spectrographs and detectors have increased the quality of the spectra obtained with these measurements. The main sources of spectral background in many biological Raman measurements are autofluorescence and other emissions from the sample itself. In such cases, the spectral signal to noise ratio (SNR) can dictate the level of error, especially regarding the low concentrations of biochemical compounds under analysis. Maximizing the SNR therefore becomes essential. For a given sample, the 
choice of excitation wavelength determines the intrinsic ratio of background emission to Raman signal. For optimal SNR, this ratio should be as low as possible. In biological applications, where most fluorophores emit significantly in the spectral region of the visible, this often drives the use of near-infrared excitation. As wavelength increases, however, the Raman cross section drops and silicon detectors become less efficient, placing some constraints on the excitation wavelength [33].

\section{The Raman spectrum}

The Raman spectrum shows intensity as a function of frequency difference between the incident and the scattered light (Raman shift). A Raman spectrum of a given molecule consists of a series of peaks or bands each shifted by one of the characteristic vibrational frequencies of each specific chemical compound. Each molecule has its own peculiar spectrum and, in this way, a Raman spectrum can provide a "fingerprint" of a substance from which molecular composition can be determined. Furthermore, the intensity of a band is proportional to the concentration of the molecule from which the band arises. For instance, proteins, nucleic acids, polysaccharides and carotenoids have their own set of characteristic bands [34].

\section{Raman spectroscopy employed in the diagnosis of atherosclerosis}

Atherosclerotic cardiovascular disease is the primary cause of mortality in the western world and is predicted to continue as such well into the twenty-first century. However, the current diagnostic standard, $\mathrm{X}$-ray angiography, along with other techniques that observe arterial stenosis, is unable to detect the vulnerable atherosclerotic plaques responsible for the majority of acute vascular incidents [35]. In fact, vulnerable plaques, which are responsible for most acute ischemic events, are presently invisible to $\mathrm{X}$-ray angiography. Their primary morphological features include a thin or ulcerated fibrous cap, a large necrotic core, superficial foam cells and intraplaque hemorrhage [36].

The rupture of unstable atherosclerotic plaque in coronary arteries accounts for the majority of fatal myocardial infarctions [37]. In this context, it is relevant to register that to date, the most advanced applications of Raman spectroscopy focused on tissues are in atherosclerotic vascular disease. Current atherosclerosis research is directed to unstable plaques, with a thin fibrous cap overlying a large pool of necrotic lipid material (atheroma core) comprised largely of cholesterol [38].

Recent studies have shown that chemical composition and morphology, rather than anatomy (degree of stenosis), determine atherosclerotic plaque instability and predict disease progression and the risk of life-threatening complications such as thrombosis and acute plaque hemorrhage. The progression and regression of atherosclerotic plaques appear to be related to the amount and type of lipids that accumulate in the interior of the arteries [39]. Actually, studies have demonstrated that up to $70 \%$ of acute cardiac ischemic events result from the rupture of previously sub-symptomatic lesions, ending in thrombotic occlusion and, frequently, myocardial infarction [36]. A number of studies have shown that quantitative chemical information regarding lesion composition can be acquired from Raman spectra of normal and atherosclerotic arterial tissue using mathematical modeling [37,38,40].

Interesting works have focused on the chemical analysis of the human coronary artery [41]. The authors of this work propose a method for in situ chemical analysis of the coronary artery by Raman spectroscopy, through the quantification of cholesterol, cholesterol esters, triglycerides, phospholipids 


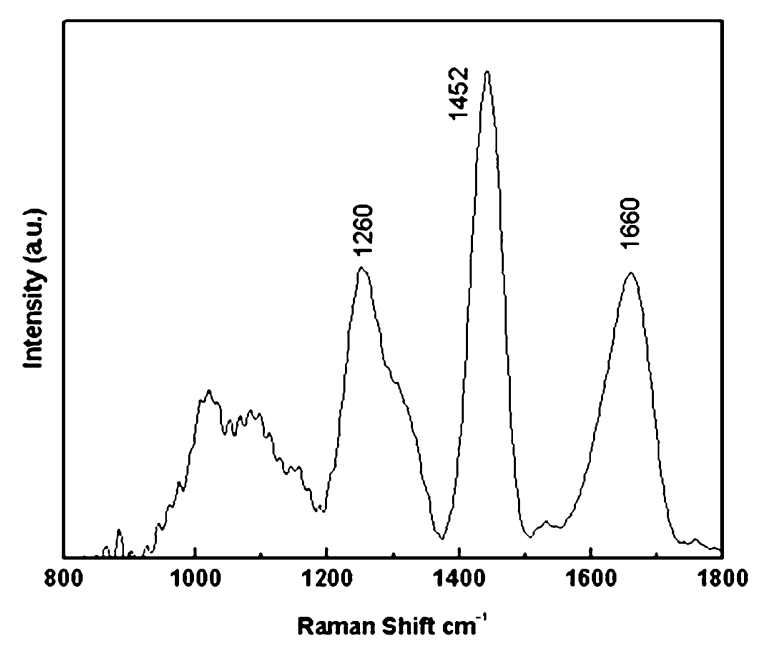

(a)

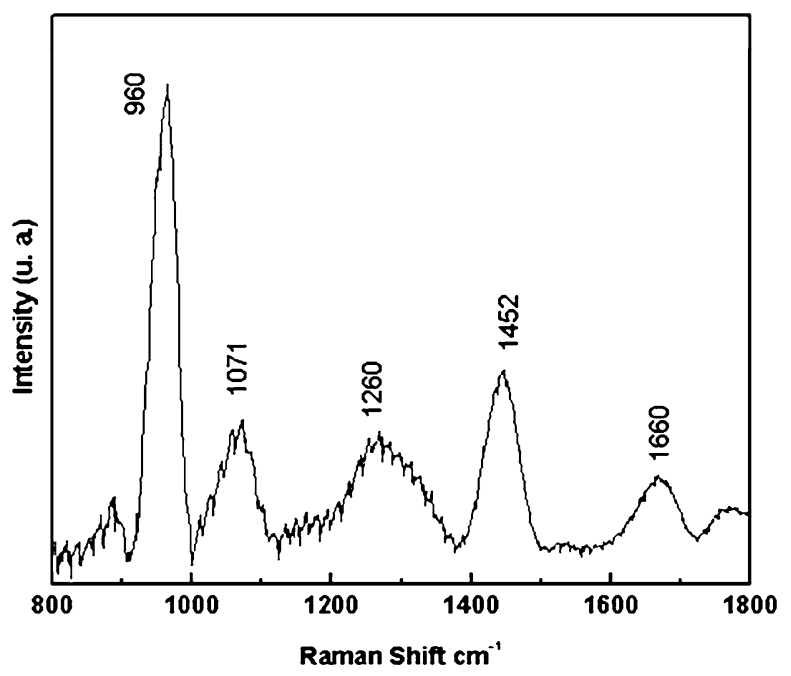

(b)

Fig. 3. (a) Raman spectrum of normal aortic valve obtained in vitro with $830 \mathrm{~nm}$ excitation; (b) Raman spectrum of calcified aortic valve obtained in vitro with $830 \mathrm{~nm}$ excitation.

and calcium salts, obtaining excellent data. It is also interesting to cite the work of Nogueira and coworkers [18], which evaluated 75 carotid fragments using FT-Raman, elaborating a comparative study with the data originated from histopathology, as well as other researches [42-44] focused on human coronary arteries that analyzed interesting phenomena by Raman spectroscopy, such as the calcification of atherosclerotic plaques.

Figure 3 illustrates the Raman spectrum of normal and calcified aortic valves, respectively. In fact, Fig. 3(b) presents great intensity in the band in approximately $960 \mathrm{~cm}^{-1}$ that is typical of calcified biological tissues, which does not appear in Fig. 3(a) that corresponds to the normal tissue. Figure 4, similarly, demonstrates the spectral difference between normal carotid artery (A) and that with calcified atheromatous plaques (B), which presents an intense spectral line in $960 \mathrm{~cm}^{-1}$. Figure 5 shows Raman spectra of fatty plaque (A) and fibrous fatty plaque (B), denoting a different spectral profile that indicates the fibrous character of the second spectrum. Therefore, it is evident the difference between the normal spectra and those that present pathological alterations. Indeed, the fingerprint bands clearly allow identifying the occurrence of cardiovascular diseases.

\section{Raman spectroscopy employed in the biochemical analysis of biological fluids}

Vibrational spectroscopies have been also applied in order to evaluate biochemical alterations in body fluids, such as blood and urine. Indeed, several works have used Raman spectroscopy to analyze the presence of molecules that are biologically important, such as glucose, in urine [45,46]. Actually, the proportion of diabetics is $6.0 \%$ in the world population. Diabetics have to monitor their glucose concentration in blood or urine continuously and this process is usually very incommodious to the patients [46]. In order to simulate abnormal diluted urine in a toilet bowl, Park and co-workers [45] diluted normal urine ten-fold with water and added glucose up to $8 \mathrm{mg} \mathrm{dl}^{-1}$. The accuracy of the classification in healthy or pathological samples was around $92 \%$, denoting the potential of this kind of application to Raman spectroscopy. 


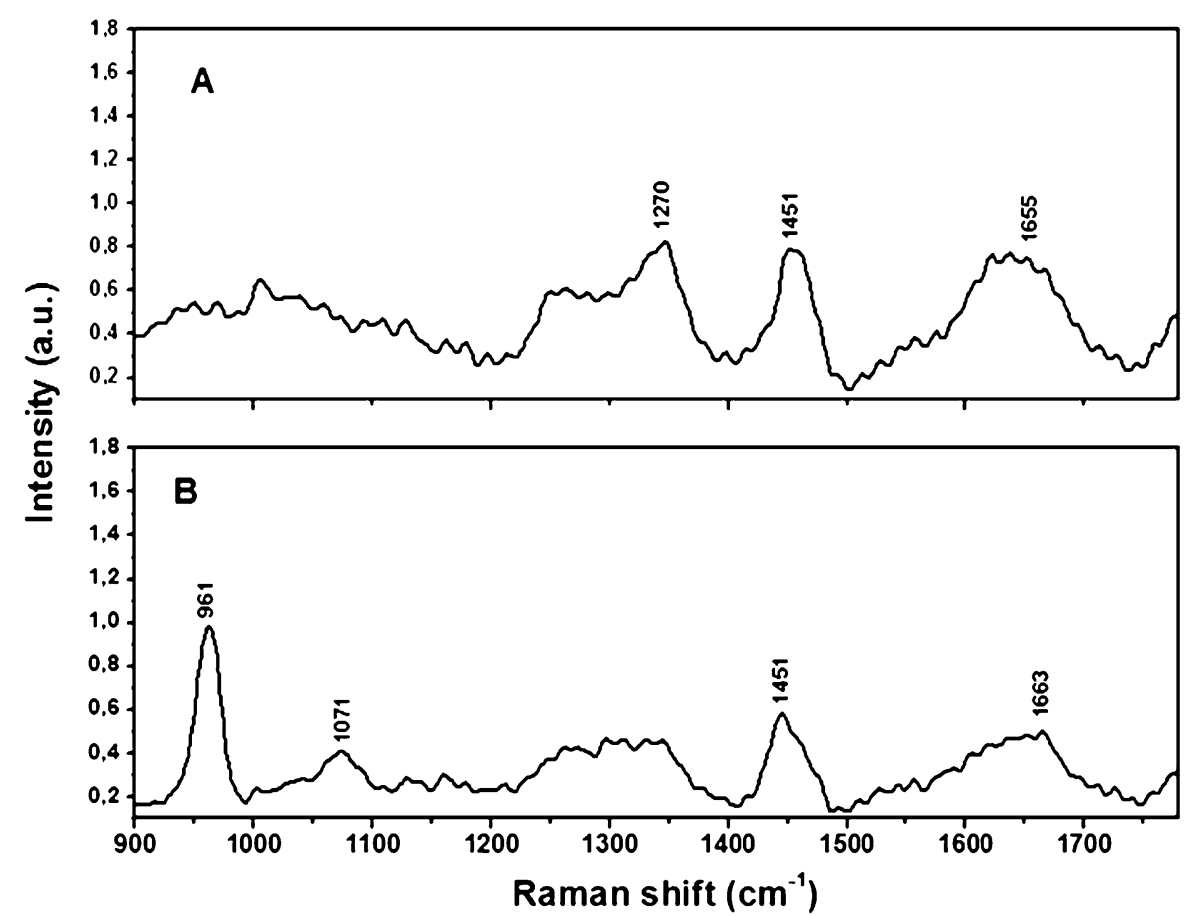

Fig. 4. Raman spectra of normal carotid artery (A) and calcified atheromatous plaques (B) obtained in vitro with $830 \mathrm{~nm}$ excitation.

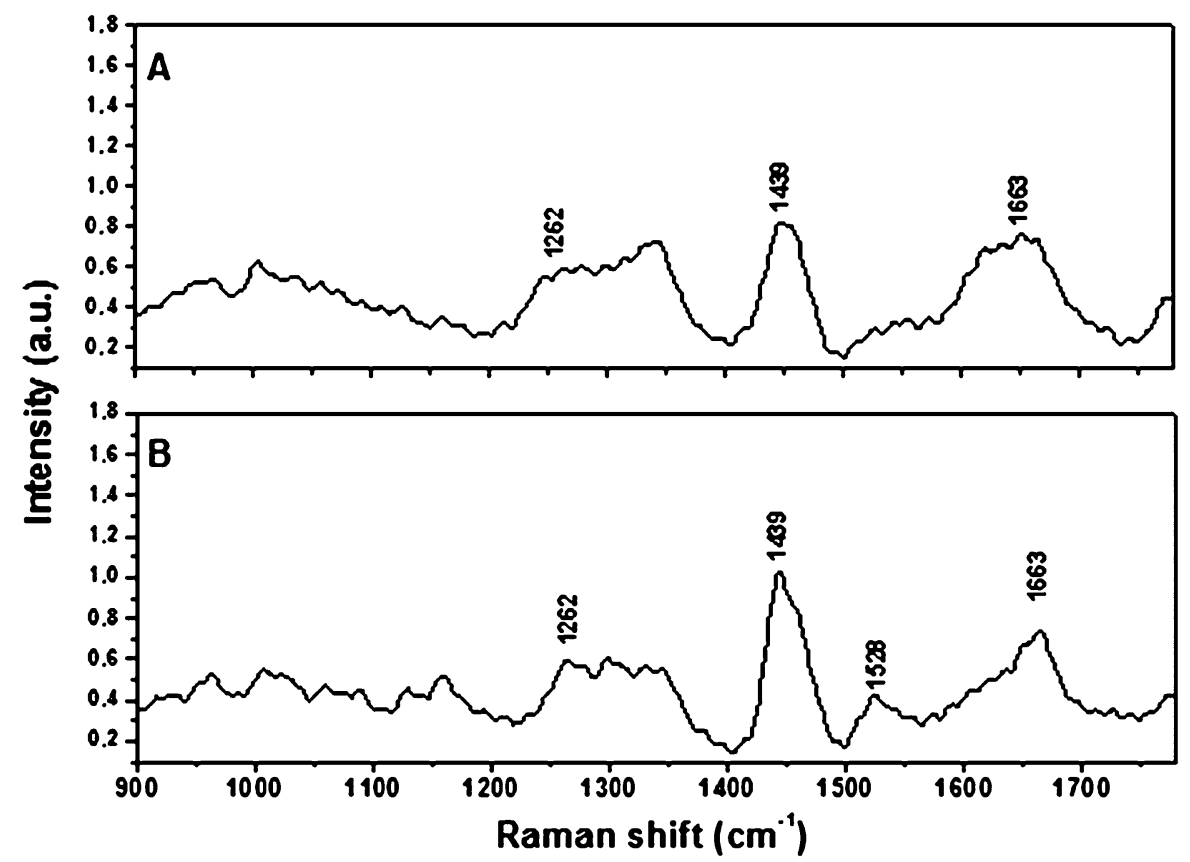

Fig. 5. Raman spectra of fatty plaque (A) and fibrous fatty plaque (B) obtained in vitro with $830 \mathrm{~nm}$ excitation. 
In this context, it is interesting to notice the quantitative infrared spectroscopic analysis that can be carried out on blood serum to determine the relative amounts of lipid present in the sample. Triglycerides, phospholipids and cholesteryl esters are the classes of lipid that occur in blood serum. These compounds occur naturally in concentrations which infrared analysis attractive, and some minimum preliminary separation is necessary. These classes of compounds can be characterized using infrared spectroscopy by their carbonyl bands. The peak maxima are usually $1742 \mathrm{~cm}^{-1}$ to trigyceride, $1737 \mathrm{~cm}^{-1}$ to phospholipids, $1723 \mathrm{~cm}^{-1}$ to chlolesteryl ester [47].

\section{Raman spectroscopy employed in the characterization of mineralized tissues and diagnosis of bone fractures}

Mineralized tissues found in vertebrates can be subdivided into those which develop through normal physiologic processes, such as bones, teeth and calcified cartilage, etc. and those formed through pathologic processes as, for example, atherosclerotic plaques, kidney and salivary stones, and other pathologic deposits [48]. Natural calcifications are present as a mineralization product in bone, and consist of the specific mineral hydroxyapatite, while pathological calcifications are associated with many medical conditions such as diabetes, breast cancer and crystals-associated osteoarthritis [49].

All the physiologic deposits contain an analogue of the naturally occurring mineral, hydroxyapatite. Because the spectra of these mineral components are quite distinct, vibrational spectroscopy, including Raman and infrared spectroscopies, has been extensively used to evaluate all of these tissues providing information on the nature of the mineral phases present in the respective biological material. Furthermore, quantitative information on the changes in mineral composition as well as about the amounts of substituents in the mineral can be achieved $[48,50]$.

Bone fractures are lesions of distinct etiology, which, in some cases, can be associated to bone losses. There are several options to the treatment of the bone fractures, such as the use of biomaterials and laser therapy. This latter clinical procedure has demonstrated to improve bone healing on various models. In this context, Raman spectroscopy has been used as tool to the characterization of the incorporation of calcium hydroxyapatite (CHA in the range of $958-960 \mathrm{~cm}^{-1}$ ) on the repair of complete fractures of several bones, such as tibia of rabbits [51,52]. Indeed, hydroxyapatite and fluoroapatite can be characterized by Raman spectroscopy with high accuracy [53].

Interesting studies have also been published focused on dental research analysed through RS, encountering consistent data with respect to the mineral/chemical composition of the teeth. Actually, the high intensity of Raman lines assigned to $\mathrm{CaF}_{2}$ allows a detailed evaluation [54]. Other types of approach evaluating calcinosis cutis, which is characterized by the deposition of calcium salts in the subcutaneous tissues, have also been characterized by Fourier transform infrared (FTIR) and Raman microspectroscopic analysis. These studies detected skin calcified deposit (SCD) and the Raman spectra contributed significantly in this work identifying the fingerprint bands of collagen at 1,665 and $1,450 \mathrm{~cm}^{-1}$ and $\beta$-carotene at 1,519 and $1,156 \mathrm{~cm}^{-1}$ [55].

\section{Microbial identification employing Raman spectroscopy}

The quick identification of pathogenic microorganisms has been a point of concern for microbiologists and clinicians. It corresponds to a critical step for the treatment of infections. Most systems available for microbial identification are based on biochemical, physiological and morphological proofs. These 
procedures are time consuming, requiring one to five days between the receipt of patient material by the laboratory to the answer to the clinician [56]. Recently, methods based on molecular biology, such as amplification of a specific gene sequence by PCR have been developed. Although genotypic approaches can be faster and more accurate than traditional biochemical profiling, they still require DNA extraction from pure cultures and involve the consumption of expensive reagents. Due to the long periods necessary for correct microbial identification, clinicians usually start an empirical therapy while awaiting laboratorial results. According to Kolef [57], 10 to 30\% of patients with septicemia do not receive the correct antimicrobial therapy and the mortality rates in this group of patients is $30-60 \%$ higher than among patients who received the appropriate therapy from the beginning.

Several spectroscopic techniques have been recently applied for microbial identification, such as fluorescence spectroscopy [58]. In this context, the methods based on Fourier transformed (FT)-infrared (IR) spectroscopy and Raman have been considered suitable procedures of analysis for application as routine laboratorial procedures [56,59-62]. The advantages of such techniques are innumerous. Vibrational spectroscopic techniques require minimum sample handling, no consumption of reagents (as in molecular genetic approaches) and are well suited to automation because it can be used by nonexperts. Besides, a very small inoculum is necessary and the time expend on identification can be significantly reduced in comparison with conventional methodologies. Within 6 to 8 hours from inoculation on a solid medium, most pathogens form microcolonies that can be identified by Raman spectroscopy $[56,63]$.

Several studies have been carried out with the aim to identify bacterial pathogens using Raman spectroscopy. Maquelin [56] demonstrated an accurate identification of pathogens recovered from blood samples using the vibrational techniques. Rösh [60] described the identification of single bacteria by means of a micro-Raman analysis. Actually, several groups have reported the identification of bacteria employing Raman [59,62-66]. Besides, other methodologies derived from Raman spectroscopy, such as UV resonance Raman spectroscopy [67,68] and surface enhanced Raman spectroscopy $[69,70]$ have also been applied for bacterial identification.

Fungal identification can be even more complicated than the identification of bacterial pathogens. Frequently, morphological features, such as spores and conidia are determinant characteristics of a species and laboratories might need an expert mycologist for the identification of clinical specimens. Raman spectroscopy has emerged as a promising tool for this procedure. De Gussen [71] demonstrated the application of such technology for identification of filamentous fungi species. According to these authors, with an optimization of Raman spectroscopy, the method can be an accessible tool for non professional mycologists, although without replace classic proofs. Furthermore, yeasts identification has been carried out employing vibrational spectroscopy techniques. Maquelin et al. [72] developed a method for the identification of Candida species with Raman microspectroscopy. Similarly, Ibelling (2005) employed Raman spectroscopy to identify Candida spp. in peritonitis patients, and Roch $[73,74]$ studied the intracellular variation and single yeast identification using this technology.

On the other hand, besides the microbial identification studies, RS has been employed associated to others techniques focused on spectroscopic and biochemical characterization of several relevant molecules produced by microorganisms [75].

Furthermore, it is important to notice interesting approach focused on the immunologic diagnosis of toxoplasmosis through Raman spectroscopy. In fact, this important parasitary disease is identified by RS via analysis of specific antibodies against Toxoplasma gondii, such as IgG and IgM [76,77]. 


\section{Raman spectroscopy employed in the characterization of alterations in proteins and nucleic acids}

Protein and nucleic acids are crucial materials in all life activities. The study of their structure and dynamic characteristics is one of the important fields in life science and molecular physics [78].

Vibrational spectroscopies, including Raman and infrared absorption, are often used to characterize, for example, the nature of drug-nucleic acid interactions and to monitor the effects of several drugs on DNA or RNA structures [79].

It is interesting to notice the relevance of the characterization by Raman spectroscopy of perturbations that occur in the DNA conformations induced by different intra-stand adducts of antitumor, such as cisplatin, since this drug is an important resource against cancer [80]. Other antitumor agents have also been used to bind to specific sequences of DNA, promoting, consequently, single and double cleavage [81]. Indeed, Raman spectroscopy has been also able to analyze the interaction of important biomolecules, such as histamine, with DNA [82]. Similarly, the interaction between DNA and chemotherapeutic agents, such as acridine and acridine derivatives has been well-characterized by Raman spectroscopy [83]. This wide application is due to the fact that the nucleic acids demonstrate many lines in the Raman spectrum and by using these lines, the progress of conformation changes or interactions can be followed [84].

Antiviral agents, such as amantadine, which inhibits viruses of influenza B, rubeola and others also present interaction with nucleic acids, being, in the same way, characterized by Raman spectroscopy [79].

Several studies using the association of the vibrational techniques, Raman and infrared absorption spectroscopies, have also been employed with auspicious results regarding the interaction between DNA and drugs, such as polyamines $[85,86]$.

The structure and physico-chemical properties of proteins and nucleic acids change with temperature so that their biological functions are affected. This significant influence is also identified and characterized by Raman spectroscopy. In fact, the wave numbers of many vibrational modes were found to increase with lower temperature, which emphasizes the high sensitivity of this technique to detect small modifications in the arrangement of these biological macromolecules [78].

The characterization of proteins and nucleic acids has been used in order to contribute in the diagnosis of cancer. Raman spectra referent to malignant tumors exhibit relatively stronger bands regarding biological macromolecules when compared with the normal tissue, suggesting the presence of additional biomolecules such as protein (stronger amide III and I), lipids $\left(1100,1300 \mathrm{~cm}^{-1}\right)$, and DNA (1340, $1470 \mathrm{~cm}^{-1}$ ) [87].

\section{Raman spectroscopy employed in the diagnosis of skin diseases}

Raman spectroscopy has been applied in the diagnosis and biochemical analysis of several skin diseases. Besides the various tumors that occur in skin, other dermatological diseases are identified with details by RS.

RS has been also applied, in association with fluorescence spectroscopy, in the diagnosis of vitiligo [88]. Actually, the interesting work of Schallreuter and co-workers reports that FT-Raman spectroscopy identified the presence of hydrogen peroxide $\left(\mathrm{H}_{2} \mathrm{O}_{2}\right)$ in the concentration range of milimolar and fluorescence spectroscopy demonstrated $\mathrm{H}_{2} \mathrm{O}_{2}$-mediated oxidation of tryptophan residues in the depigmented 
area. The results were indicative of vitiligo, which is a disease of difficult diagnosis, denoting the relevance of this approach [88].

Psoriasis is another skin disease characterized by the association between RS and infrared spectroscopy. Bernard and co-workers [89] studying the stratum corneum, which is a very important permeability barrier for the skin, identified the higher permeability and lower assembly of the stratum corneum of psoriatic patients when compared with the normal stratum corneum. The authors analyzed the physico-chemical properties of the different samples through vibrational spectroscopies, denoting that this approach is suited to improve the understanding of the mechanisms of this pathology. Therefore, this kind of study could favor future applications in the clinical treatment of psoriasis.

It is important to register the use of vibrational microscopy and imaging to analyze a variety of dermatological applications. Phosphodiester, cytosine, DNA, keratin and other skin compounds present spectral signatures well-characterized by RS [90].

\section{Raman spectroscopy employed in the diagnosis of cancer}

Malignant tumor is one of the most dangerous diseases menacing human beings. Effective prevention and treatments of various cancers, such as chemotherapy, have been the subject of many investigations. With the increasing number of compounds synthesized as potential anticancer drugs, systematic screening methods are necessary for classification of these compounds in agreement with their anticancer activities. These methods can be in vivo and in vitro, being that the in vivo methods are often more accurate but rather expensive and time-consuming, while the in vitro methods are simpler and more rapid, but with lower precision and cost [91]. In this context, it is important to notice the employment of spectroscopic techniques like, for example, fluorescence emission spectroscopy, which is able to differentiate normal and neoplastic human tissue [92].

All cancer stages are followed by fundamental changes in cellular morphology and/or tissue biochemistry. The biochemical tumor makers such as proteins, enzymes and hormones could be detected by analyzing the differences of Raman spectra taken from normal and pathological tissues [93]. Manoharam and co-workers [32] reported that Raman spectroscopy has a potential to identify biological labels associated with the malignant changes, which may provide useful qualitative and quantitative information for use in tumor classification, grading and evolution, helping in diagnosis and prognosis of the cancer. Choo-Smith and co-workers [94] reported that many of the biochemical changes in a neoplastic tissue, such as increases in the respective concentrations of protein and nucleic acids and decrease in the one of the lipid components could be detected by Raman spectroscopy (RS).

In fact, Raman spectroscopy (RS) has provided relevant information on peptides and DNA backbone conformations as well as selected side-chain interaction. Thus, RS can be applied in cancer biology in order to detect specific changes in the structure of DNA or proteins, implying that this spectroscopic technique can evaluate the chemotherapeutic action of several drugs [95].

Cancer of uterine cervix, for example, has been analyzed with success by Raman spectroscopy through its fingerprint region. In fact, normal cervix tissues are characterized by strong and broad amide I, broader amide III and strong peaks at 853 and $938 \mathrm{~cm}^{-1}$, which are assigned to structural proteins of this tissue, such as collagen. Prominent features of malignant tissue spectra when compared with the normal tissue are the relatively weaker and sharper amide I, minor red shift in $\Delta \mathrm{CH}_{2}$ and sharper amide III, which indicate the presence of DNA, lipids and non-collagenous proteins [21]. Recently, several interesting works have focused on different methodologies of employment of Raman spectroscopy 
in order to discriminate cancer cells and normal cells [96,97]. In fact, efforts have been developed in order to define a standard RS spectrum to the healthy tissues of several parts of the human organism. For instance, normal colorectal tissue has been evaluated by RS as a pre-requisite step to the subsequent diagnosis of the cancerous tissue [98].

Several works have been published focused on human breast tissues. These articles demonstrated spectral differences between malignant, benign and normal tissues. Actually, it was found differences between peak intensities that were assigned to the alterations of the fatty acids and $\beta$-carotene contents $[99,100]$.

It can be cited the employment of RS in order to gain insight into the biochemical composition of cells and tissues with cervical cancer, since RS can evaluate with great accuracy the signals assigned to proteins, nucleic acids, lipids and carbohydrates. In fact, cervical cancer is the second most common cancer among women worldwide and generally is more frequent in developing countries. Recent results show that RS displays a high sensitivity to cervical tissue, invasive carcinoma and cervical intraepithelial neoplasia (CIN) [101].

In this way, near-infrared Raman spectroscopy has been applied for diagnosis of several kinds of tumors, such as oral carcinoma [102] and excellent clinical advancements can be obtained with this employment.

\section{Instrumental advancements in Raman spectroscopy to biomedical applications}

Many medical applications require remote sampling by use of optical fibers in which the sizes of the probe and the fiber bundle are strictly limited by anatomic aspects. For example, the ability to clinically evaluate coronary atherosclerosis and breast cancer requires probes that present $\sim 2 \mathrm{~mm}$ or less of diameter to be incorporated into standard cardiovascular catheters or configured for optical needle biopsy. Similar constraints are presented with endoscopic employments, in which the probe should be inserted into a narrow-diameter channel. In addition, data acquisition time must be limited to a few seconds [37]. Figure 6 represents a model of Raman spectroscopy instrument with the presence of an optical fiber.

Thus, practical implementation of Raman spectroscopy requires an integrated instrument that can provide, preferentially, real-time spectral analysis and diagnostic information to the clinician. Previously

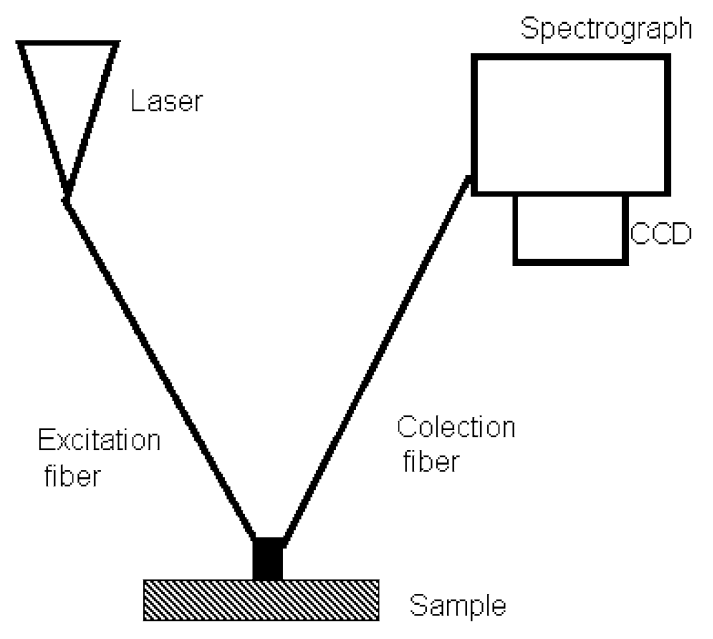

Fig. 6. Endoscopic needle probe scheme. 
described Raman systems served as proof of principles for these concepts. Actually, using a commercially available probe to take spectra from human finger, arm, nail, tooth and tongue with acquisition times of 5 seconds, custom-built software was able to provide accurate classification of the different tissue types within 1 second after acquisition [103].

Low-OH fused silica has been determined as the optimal fiber substrate for use in the near infrared. The necessity for designing proper optical filters to remove the probe background has been established and numerous probe configurations have been explored [37].

In this context, it is interesting to note that in vivo applications of Raman spectroscopy, in most cases, requires the use of a flexible light guiding device of small diameter, such that it can for instance be introduced in the working channel of an endoscope or inside a biopsy needle or biopsy forceps. The fiberoptic probe must guide light to the tissue under investigation, collect light that is scattered by the tissue, and transport this collected light from the tissue to a device of spectral analysis. Successful steps towards techniques applied in vivo, by means of fiberoptic probes have been reported by authors that collected in vivo spectra from human cervical tissue for the clinical diagnosis of cervical precancers [104].

Although its use has been spread in the biomedical area, Raman spectroscopy has some limitations, since the diagnostic results can only be obtained when the signal-to-noise ratio (SNR) is above of 10 . There are problems due to sample handling on in vivo experiments, which cannot be accessed directly with standard, non-fiber optic coupled Raman systems. In this way, novel optical catheters using fiberoptics especially designed for Raman spectroscopy have been developed. These catheters have improved the perspectives to a wide range of applications in biomedicine, such as the diagnosis of pathologies in vivo, usually called "optical biopsy" [105-108]. Actually, these studies have proposed the development of an optical catheter with bending control of the distal end. The probe consists of seven optical fibers wrapped in a resin and a biocompatible flexible Teflon tube with a novel mechanical device that allows bending of the distal extremity to access a desired location of a human organ [109].

In fact, the feasibility and diagnostic potential of a fiberoptic near-infrared Raman spectroscopy system has been demonstrated during recent endoscopies, in which differentiation of colon polyps was achieved with high accuracy [17].

Raman spectroscopy is traditionally a surface technique; however, methods that permit its application for obtaining sample composition to clinically relevant depths of many millimeters have been developed. Indeed, Stone and co-workers [110], for example, reported the first demonstration of spatially offset Raman spectroscopy (SORS) for potential in vivo breast analysis. This study evaluates the possibility of utilizing SORS for measuring calcification composition through varying thicknesses of tissues (2-10 mm), which are about one to two orders of magnitude deeper than has been possible with conventional Raman approaches. SORS can be used to distinguish non-invasively between calcification types I and II (and carbonate substitution of phosphate in calcium hydroxyapatite) within tissue of up to $10 \mathrm{~mm}$ deep.

In this way, optical fiber has been applied associated to RS in different approaches in order to obtain more accessibility and information from several biological tissues [111].

\section{Other spectroscopies based on the Raman effect}

Resonance Raman spectroscopy (RRS) has been widely used for the research of the insertion of drugs to DNA because of its sensitivity to the structure of drug/DNA compounds, and its selectivity which 


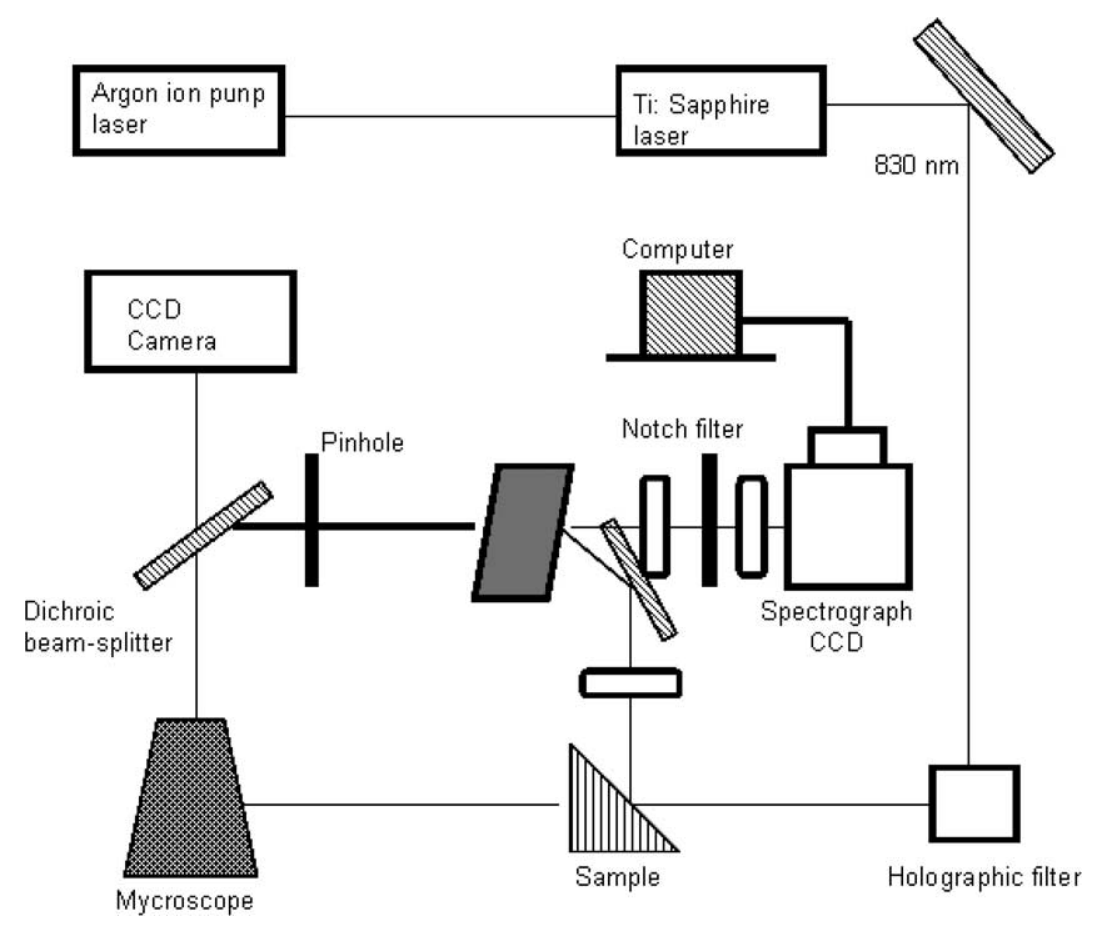

Fig. 7. Schematic representation of confocal Raman microspectroscopy.

permits only the observation of bands corresponding to the vibrations of the chromophoric framework. This method presents two main limitations: the corresponding laser is required to make the exciting wavelength only in the electronic absorption band of compounds, which is not convenient in practical operation; and, the inherent fluorescent effects of samples have not been well solved [112].

One technique to overcome these difficulties is surface-enhanced Raman spectra (SERS). Actually, SERS can be used in order to screen out anticancer drugs [112].

It important to emphasize the importance of the applications of Raman confocal microspectroscopy in the analysis of microcolonies for the earlier identification of microorganisms. The instrumental arrangement of this method is represented by Fig. 7.

Furthermore, the interaction of several chemical compounds, such as metal complexes, with DNA has generated considerable interest regarding the development of DNA conformational probes, artificial nucleases, hybridization sensors, and anti-cancer drugs. Besides, spectroscopic techniques based on Raman effect, such as resonance Raman spectroscopy (RRS) have been employed as tool of choice in this kind of analytical approach [113].

\section{Conclusion}

The new biomedical applications of Raman spectroscopy (RS) are in constant improvement. The future perspectives are excellent in order to increase the possibilities of identification, characterization, and even quantification of the biological materials through this spectroscopic tool. This occurs due to the ability of RS to determine slight molecular structure alterations of the biological samples, allowing wide studies involving activity-function relationship of the biological molecules, including that are 
associated to the pathologic manifestations. These possibilities constitute focus of interest of several research groups. Indeed, this wide potential of biochemical analysis and diagnosis makes this respective employment of RS a very interdisciplinary subject. Attempts of application in vivo have been developed by several groups. Therefore, it is necessary a more wide divulgation of these studies in order to improve the clinical treatments and the quality of life of the patients that present some of the several diseases that can be identified by Raman spectroscopy.

\section{References}

[1] B. Swinson, W. Jerjes, M. El-Maaytah, P. Norris and C. Hopper, Optical techniques in diagnosis of head and neck malignancy, Oral Oncol. 42 (2006), 221-228.

[2] J.M. Reyes-Goddard, H. Barr and N. Stone, Photodiagnosis using Raman and surface enhanced Raman scattering of bodily fluids, Photodiagn. Photodyn. Ther. 2 (2005), 223-233.

[3] H. Zeng, A. McWilliams and S. Lam, Optical spectroscopy and imaging for early lung cancer detection: a review, Photodiagn. Photodyn. Ther. 1 (2004), 111-122.

[4] J.W. Tunnell, A.W. Haka, S.A. McGee, J. Mirkovic and M.S. Feld, Diagnostic tissue spectroscopy and its applications to gastrointestinal endoscopy, Tech. Gastrointest. Endosc. 5 (2003), 65-73.

[5] A.M. Rollins and M.V. Sivak, Potential new endoscopic techniques for the earlier diagnosis of pre-malignancy, Best Pract. Res. Clin. Gastroenterol. 15 (2001), 227-247.

[6] R.A. Zângaro, L. Silveira, Jr., R. Manoharan, G. Zonios, I. Itzkan, R.R. Dasari, J. VanDam and M.S. Feld, Rapid multiexcitation fluorescence spectroscopy system for in vivo tissue diagnosis, Appl. Opt. 35 (1996), 5211-5219.

[7] L. Silveira, Jr., J. VanDam, R.A. Zângaro, G. Zonios, R. Manoharan, J.M. Crawford, J. Vandervoort, I. Itzkan and M.S. Feld, In vivo multi-excitation fluorescence spectroscopy for the detection of colonic dysplasia, Gastrointest. Endosc. 43 (1996), 54-54.

[8] M. Pons, S. Le Bonté and O. Potier, Spectral analysis and fingerprinting for biomedia characterization, J. Biotechnol. 113 (2004), 211-230.

[9] C.M. Krishna, N.B. Prathima, R. Malini, B.M. Vadhiraja, R.A. Bhatt, D.J. Fernandes, P. Kushtagi, M.S. Vidyasagar and V.B. Kartha, Raman spectroscopy studies for diagnosis of cancers in human uterine cervix, Vibr. Spectrosc. 41 (2006), 136-141.

[10] D. Rohleder, G. Kocherscheidt, K. Gerber, W. Kiefer, W. Köhler, J. Möcks and W. Petrich, Comparison of mid-infrared and Raman spectroscopy in the quantitative analysis of serum, J. Biomed. Opt. 10 (2005), 031108.

[11] R.A. Shaw and H.H. Mantsch, Vibrational biospectroscopy: from plants to animals to humans. A historical perspective, J. Mol. Struct. 480/481 (1999), 1-13.

[12] S. Wartewig and R.R.H. Neubert, Pharmaceutical applications of Mid-IR and Raman spectroscopy, Adv. Drug Deliv. Rev. 57 (2005), 1144-1170.

[13] L. Silveira, Jr., S. Sathaiah, R.A. Zângaro, M.T.T. Pacheco, M.C. Chavantes and C.A.G. Pasqualucci, Correlation between near-infrared Raman spectroscopy and the histopathological analysis of atherosclerosis in human coronary arteries, Lasers Surg. Med. 30 (2002), 290-297.

[14] A.E. Guimarães, M.T.T. Pacheco, L. Silveira, Jr., D. Basottini, J. Duarte, A.B. Villaverde and R.A. Zângaro, Near Infrared Raman Spectroscopy (NIRS): A technique for doping control, Spectroscopy 20 (2006), 185-194.

[15] H.P. Buschman, G. Deinum, J.T. Motz, M. Fitzmaurice, J.R. Kramer, A. van der Laarse, A.V. Bruschke and M.S. Feld, Raman microspectroscopy of human coronary atherosclerosis: Biochemical assessment of cellular and extracellular morphologic structures in situ, Cardiovasc. Pathol. 10 (2001), 69-82.

[16] A. Shen, Z.L.H. Wang, I. Goan, Y. Wy, X. Wang, Z. Yu and J. Hu, Study on the in vitro and in vivo activation of rat hepatic stellate cells by Raman spectroscopy, J. Biomed. Opt. 12 (2007), 034003.

[17] P. Crow, A. Molckovsky, N. Stone, J. Uff, B. Wilson and L.M. Wongkeesong, Assessment of fiberoptic near-infrared Raman spectroscopy for diagnosis of bladder and prostate cancer, Urology 65 (2005), 1126-1130.

[18] G.V. Nogueira, L. Silveira, Jr., A.A. Martin, R.A. Zângaro, M.T.T. Pacheco, M.C. Chavantes and C.A. Pasqualucci, Raman spectroscopy study of atherosclerosis in human carotid artery, J. Biomed. Opt. 10 (2005), 03111.

[19] J.R. Beattie, S. Brockbank, J.J. McGarvey and W.J. Curry, Raman microscopy of porcine inner retinal layers from the area centralis, Mol. Vis. 13 (2007), 1106-1113.

[20] J.R. Baena and B. Lendl, Raman spectroscopy in chemical bioanalysis, Curr. Opin. Chem. Biol. 8 (2004), 534-539.

[21] C.M. Krishna, G.D. Sockalingum, G. Kegelaer, S. Rubin, V.B. Kharta and M. Manfait, Micro-Raman spectroscopy of mixed cancer cells populations, Vibr. Spectrosc. 38 (2005), 95-100. 
[22] A.A. Martin, R.A.B. Carter, L.O. Nunes, E.A.L. Arisawa and L. Silveira, Jr., Principal components analysis of FT-Raman spectra of ex vivo basal cell carcinoma, Biomed. Vibr. Spectrosc. 5321 (2004), 198-204.

[23] S. Pilotto, M.T.T. Pacheco, L. Silveira, Jr., A.B. Villaverde and R.A. Zângaro, Analysis of near-infrared Raman spectroscopy as a new technique for a transcutaneous non-invasive diagnosis of blood components, Lasers Med. Sci. 16 (2001), 2-9.

[24] F.G. Benício, M.T.T. Pacheco, M.R. Rodrigues, A.B. Villaverde, E. Munin, L. Silveira, Jr. and R.A. Zângaro, Near infrared Raman spectroscopy system for real time monitoring of fast processes: A resin composite photopolymerization application, Instr. Sci. Technol. 35 (2007), 609-617.

[25] P. Matousek, Deep non-invasive Raman spectroscopy of living tissue and powders, Chem. Soc. Rev. 36 (2007), 12921304.

[26] F.B. Souza, M.T.T. Pacheco, A.B. VilaVerde, L. Silveira, Jr., R.L. Marcos and R.A.B. Lopes-Martins, Avaliação do Ácido Lático Intramuscular através de Espectroscopia Raman: novas perspectivas em medicina do esporte, Rev. Bras. Med. Esp. 9 (2003), 388-395.

[27] J. Chaiken, W. Finney, P.E. Knudson, R.S. Weinstock, M. Khan, R.J. Bussjager, D. Hagrman, P. Hagrman, Y. Zhao, C.M. Peterson and K. Peterson, Effect of hemoglobin concentration variation on the accuracy and precision of glucose analysis using tissue modulated, noninvasive, in vivo, Raman spectroscopy of human blood: a small clinical study, J. Biomed. Opt. 10 (2005), 031111.

[28] J.L. Lambert, C.C. Pelletier and M. Borchert, Glucose determination in human aqueous humor with Raman spectroscopy, J. Biomed. Opt. 10 (2005), 031110.

[29] N.J.C. Bauer, M. Motamedi, F. Hendrikse and J.P. Wicksted, Remote temperature monitoring in ocular tissue using confocal Raman spectroscopy, J. Biomed. Opt. 10 (2005), 031109.

[30] D. Pappas, B.W. Smith and J.D. Winefordner, Raman spectroscopy in bioanalysis, Talanta 51 (2000), 131-144.

[31] C. Yu, E. Gestl, K. Eckert, D. Allara and J. Irudayaraj, Characterization of human breast epithelial cells by confocal Raman microspectroscopy, Cancer Detect. Prevent. 30 (2006), 515-522.

[32] R. Manoharam, Y. Wang and M.S. Feld, Histochemical analysis of biological tissues using Raman spectroscopy, Spectrochim. Acta A 52 (1996), 215-249.

[33] D. Qi and A.J. Berger, Quantitative concentration measurements of creatinine dissolved in water and urine using Raman spectroscopy and a liquid core optical fiber, J. Biomed. Opt. 10 (2005), 031115.

[34] A. Lorincz, D. Haddad, R. Naik, V. Naik, A. Fung, A. Cao, P. Manda, A. Pandya, G. Auner, R. Rabah, S.C. Langenburg and M.D. Klein, Raman spectroscopy for neoplastic tissue differentiation: A pilot study, J. Pediatr. Surg. 39 (2004), 953-956.

[35] J.T. Motz, M. Fitzmaurice, A. Miller, S.J. Gandhi, A.S. Haka, L.H. Galindo, R.R. Dasari, J.R. Kramer and M.S. Feld, In vivo Raman spectral pathology of human atherosclerosis and vulnerable plaque, J. Biomed. Opt. 11 (2006), 021003.

[36] O.R. Scepanovic, M. Fitzmaurice, J.A. Gardecki, G.O. Angheloiu, S. Awasthi, J.T. Motz, J.R. Kramer, R.R. Dasari and M.S. Feld, Detection of morphological markers of vulnerable atherosclerotic plaque using multimodal spectroscopy, J. Biomed. Opt. 11 (2006), 021007.

[37] J.T. Motz, M. Hunter, L.H. Galindo, J.A. Gardecki, J.R. Kramer, R.R. Dasari and M.S. Feld, Optical fiber probe for biomedical Raman spectroscopy, Appl. Opt. 43 (2004), 542-554.

[38] T.J. Römer, J.F. Brennan, M. Fitzmaurice, M.L. Feldstein, G. Deinum, J.L. Myles, J.R. Kramer, R.S. Lees and M.S. Feld, Histopathology of human coronary atherosclerosis by quantifying its chemical composition with Raman spectroscopy, Circulation 97 (1998), 878-885.

[39] H.P. Bushman, J.T. Motz, G. Deinum, T.J. Römer, M. Fitzmaurice, J.R. Kramer, A. van der Laarse, A.V. Bruschke and M.S. Feld, Diagnosis of human coronary atherosclerosis by morphology-based Raman spectroscopy, Cardiovasc. Pathol. 10 (2001), 59-68.

[40] A.R. de Paula, Jr. and S. Sathaiah, Raman spectroscopy for diagnosis of atherosclerosis: a rapid analysis using neural networks, Med. Eng. Phys. 27 (2005), 237-244.

[41] J.F. Brennan, T.J. Römer, R.S. Lees, A.M. Tercyak, J.R. Kramer and M.S. Feld, Determination of human coronary artery composition by Raman spectroscopy, Circulation 96 (1997), 99-105.

[42] L. Silveira, Jr., S. Sathaiah, R.A. Zângaro, M.T.T. Pacheco, M.C. Chavantes and C.A. Pasqualucci, Near-infrared Raman spectroscopy of human coronary arteries: Histopathological classification based on mahalanobis distance, Laser Med. Surg. 21 (2003), 203-208.

[43] R. Rocha, A.B. Villaverde, C.A. Pasqualucci, L. Silveira, Jr., A. Brugnera, M.S. Costa and M.T.T. Pacheco, Identification of calcifications in cardiac valves by near Infrared Raman spectroscopy, Photomed. Laser Surg. 25 (2007), 287-290.

[44] R. Rocha, L. Silveira, Jr., A.B. Villaverde, C.A. Pasqualucci, M.S. Costa, A. Brugnera and M.T.T. Pacheco, Use of nearinfrared Raman spectroscopy for identification of atherosclerotic plaques in the carotid artery, Photomed. Laser Surg. 6 (2007), 482-486.

[45] C. Park, K. Kim, J. Choi and K. Park, Classification of glucose concentration of diluted urine using the low-resolution Raman spectroscopy and kernel optimization methods, Physiol. Meas. 28 (2007), 583-593. 
[46] C. Park, J. Choi and K. Park, Urine analysis in diluted situation using low-resolution Raman spectroscope, in: Proceedings of the 2005 IEEE Engineering in Medicine and Biology 27th Annual Conference, Shangai, China, 2005, pp. 1991-1993.

[47] B.H. Stuart and D.J. Ando, Biological Applications of Infrared Spectroscopy, Wiley, Chichester, NY, 1997; ISBN: 0471974145.

[48] A.L. Boskey and R. Mendelsohn, Infrared spectroscopic characterization of mineralized tissues, Vibr. Spectrosc. 38 (2005), 107-114.

[49] P. Matousek and N. Stone, Prospects for the diagnosis of breast cancer by noninvasive probing of calcifications using transmission Raman spectroscopy, J. Biomed. Opt. 12 (2007), 024008.

[50] Y.N. Yeni, J. Yerramshetty, O. Akkus, C. Pechey and C.M. Les, Effect of fixation and embedding on Raman spectroscopic analysis of bone tissue, Calcif. Tissue Int. 78 (2006), 363-371.

[51] C.B. Lopes, M.T.T. Pacheco, L. Silveira, Jr., J. Duarte, M.C.T. Cangussú and A.L.B. Pinheiro, The effect of the association of NIR lasertherapy BMPs, and guided bone regeneration on tibial fractures treated with wire osteosynthesis: Raman spectroscopy study, J. Photochem. Photobiol. (2008), in press.

[52] C.B. Lopes, A.L.B. Pinheiro, S. Sathaiah, N.S. Silva and M.A.C. Salgado, Infrared Laser Photobiomodulation $(\lambda 830 \mathrm{~nm})$ on bone tissue around dental implants: a Raman spectroscopy and scanning electronic microscopy study in rabbits, Photomed. Laser Surg. 25 (2007), 96-101.

[53] A. Moshaverinia, S. Ansari, M. Moshaverinia, N. Roohpour, J.A. Daar and I. Rehmam, Effects of incorporation of hydroxyapatite and fluoroapatite nanobioceramics into conventional glass ionomer cements (GIC), Acta Biomater. 4 (2008), 432-440.

[54] H. Tsuda and J. Arends, Raman spectroscopy in dental research: a short review of recent studies, Adv. Dent. Res. 11 (1997), 539-547.

[55] M. Liu, W. Cheng, M. Li, H. Liu, D. Yang and S. Lin, Identification of chemical compositions of skin calcified deposit by vibrational microspectroscopies, Arch. Dermatol. Res. 297 (2005), 231-234.

[56] K. Maquelin, C. Kirchner, L.P. Choo-Smith, N.A. Ngo-Thi, T. van Vreewijk, M. Stammler, H.P. Endtz, H.A. Bruining, D. Naumann and G.J. Puppels, Prospective study of the performance of vibrational spectroscopies for rapid identification of bacterial and fungal pathogens recovered from blood cultures, J. Clin. Microbiol. 41 (2003), 324-329.

[57] M.H. Kollef, Inadequate antimicrobial treatment: an important determinant of outcome for hospitalized patients, Clin. Infect. Diseases 31 (2000), 131-138.

[58] H.E. Giana, L. Silveira, Jr., R.A. Zângaro and M.T.T. Pacheco, Rapid identification of bacterial species by fluorescence spectroscopy and classification through principal components analysis, J. Fluoresc. 13 (2003), 489-493.

[59] L.P. Choo-Smith, T. van Vreewijk, H.A. Bruining, G.J. Puppels, N.A. Ngo-Thi, C. Kirchner, D. Naumann, D. Ami, A.M. Villa, F. Orsini, S.M. Doglia, H. Lamfarraj, G.D. Sockalingum, M. Manfait, P. Allouch and H.P. Endtz, Investigating microbial (micro)colony heterogenicity by vibrational spectroscopies, Appl. Environ. Microbiol. 67 (2001), 1461-1469.

[60] P. Rösch, M. Harz, M. Schmitt, K.D. Peschke, O. Ronnenberg, H. Burkhardt, H.W. Motzkus, M. Lankers, S. Hofer, $\mathrm{H}$. Thiele and J. Popp, Chemotaxonomic identification of single bacteria by micro-Raman spectroscopy: Application to clean-room-relevant biological contamination, Appl. Environ. Microbiol. 71 (2005), 1626-1637.

[61] M.S. Ibelings, K. Maquelin, H.P. Endtz, H.A. Bruining and G.J. Puppels, Rapid Identification of Candida spp. in peritonitis patients by Raman spectroscopy, Clin. Microbiol. Infect. 11 (2005), 353-358.

[62] M. Harz, P. Rösch, K.D. Peschke, O. Ronneberger, H. Burkhardt and J. Popp, Micro-Raman spectroscopic identification of bacterial cells of the genus Staphylococcus and dependence on their cultivation conditions, Analyst 130 (2005), 15431550.

[63] K. Maquelin, C. Kirschner, L.P. Choo-Smith, N. van den Braak, H.P. Endtz, D. Naunmann and G.J. Puppels, Identification of medically relevant microorganisms by vibrational spectroscopy, J. Microbiol. Meth. 51 (2002), 255-271.

[64] K. Maquelin, L.P. Choo-Smith, T. van Vreeswijk, H.P. Endtz, B. Smith, R. Bennett, H.A. Bruining and G.J. Puppels, Raman spectroscopic method for identification of clinically relevant microorganisms growing on solid culture medium, Anal. Chem. 72 (2000), 12-19.

[65] C. Kirschner, K. Maquelin, P. Pina, N.A. Ngo Thi, L.P. Choo-Smith, G.D. Sockalingum, C. Sandt, D. Ami, F. Orsini, S.M. Doglia, P. Allouch, M. Mainfait, G.J. Puppels and D. Naumann, Classification and identification of enterococci: A comparative phenotypic, genotypic and vibrational spectroscopic study, J. Clin. Microbiol. 39 (2001), 1763-1770.

[66] A.J. Berger and Q. Zhu, Identification of oral bacteria by Raman microspectroscopy, J. Modern Opt. 50 (2001), 23752380.

[67] E.C. López-Díez and R. Goodacre, Characterization of microorganisms using UV resonance Raman spectroscopy and chemometrics, Anal. Chem. 76 (2004), 585-591.

[68] R.M. Jarvis and R. Goodacre, Ultra-violet resonance Raman spectroscopy for the rapid discrimination of urinary tract infection bacteria, FEMS Microbiol. Lett. 19 (2004), 127-132.

[69] L.J. Goeller and M.R. Riley, Discrimination of bacteria and bacteriophages by Raman spectroscopy and surface-enhanced Raman spectroscopy, Appl. Spectrosc. 61 (2007), 679-685. 
[70] Y. Liu, Y.R. Chen, X. Nou and K. Chao, Potential of surface-enhanced Raman spectroscopy for the rapid identification of Escherichia coli and Listeria monocytogenes cultures on silver colloidal nanoparticles, Appl. Spectrosc. 61 (2007), $824-831$.

[71] K. De Gussem, P. Vandenabeele, A. Verbeken and L. Moens, Chemotaxonomical identification of spores of macrofungi: possibilities of Raman spectroscopy, Anal. Bioanal. Chem. 387 (2007), 2823-2832.

[72] K. Maquelin, L.P. Choo-Smith, H.P. Endtz, H.A. Bruining and G.J. Pupples, Rapid identification of Candida species by Confocal Raman microspectroscopy, J. Clin. Microbiol. 40 (2002), 594-600.

[73] P. Rosch, M. Harz, M. Schmitt and J. Popp, Raman spectroscopic identification of single yeast cells, J. Raman Spectrosc. 36 (2005), 377-379.

[74] P. Rösch, M. Harz, K.D. Peschke, O. Ronneberger, H. Burkhardt and J. Popp, Identification of single eukaryotic cells with micro-Raman spectroscopy, Biopolymers 82 (2006), 312-316.

[75] R. Ettrich, V. Kopecký, Jr., K. Hofbauerová, V. Baumruk, P. Novák, P. Pompach, P. Man, O. Plíhal, M. Kutý, N. Kulik, J. Sklenár, H. Ryslavá, V. Kren and K. Bezouska, Structure of the dimeric $\beta$ - $N$-acetylhexosaminidase revealed by computer modeling, vibrational spectroscopy, and biochemical studies, BMC Struct. Biol. 7 (2007), 1-14.

[76] C. Araujo-Andrade, J.L. Pichardo-Molina, G. Barbosa-Sabanero, C. Frausto-Reyes and A. Torres-López, Detection of the presence of antibodies against Toxoplasma gondii in human colostrums by Raman spectroscopy and principal component analysis, J. Biomed. Opt. 12 (2007), 034006.

[77] J. Duarte, M.T.T. Pacheco, R.Z. Machado, L. Silveira, Jr., R.A. Zângaro and A.B. Villaverde, Use of near-infrared Raman spectroscopy to detect IgG and IgM antibodies against Toxoplasma gondii in serum samples of domestic cats, Cell. Mol. Biol. 48 (2002), 585-589.

[78] R. Dong, X. Yan, X. Pang and S. Liu, Temperature-dependent Raman spectra of collagen and DNA, Spectrochim. Acta A 60 (2004), 557-561.

[79] J. Stanicová, G. Fabriciová, L. Chinsky, V. Sutiak and P. Miskovský, Amantadine-DNA interaction as studied by classical and resonance Raman spectroscopy, J. Mol. Struct. 478 (1999), 129-138.

[80] O. Vrána, V. Masek, V. Drazan and V. Brabec, Raman spectroscopy of DNA modified by intrastrand cross-links of antitumor cisplatin, J. Struct. Biol. 159 (2007), 1-8.

[81] C. Rajani, J.R. Kincaid and D.H. Petering, Raman spectroscopy of an $\mathrm{O}_{2}$-Co(II)bleomycin-calf thymus DNA adduct: alternate polymer conformations, Biophys. Chem. 94 (2001), 219-236.

[82] A.J. Ruiz-Chica, A. Soriano, I. Tuñón, F.M. Sánchez-Jiménez, E. Silla and F.J. Ramírez, FT-Raman and QM/MM study of the interaction between histamine and DNA, Chem. Phys. 324 (2006), 579-590.

[83] L. Pérez-Flores, A.J. Ruiz-Chica, J.G. Delcros, F.M. Sánchez-Jiménez and F.J. Ramírez, Intercalation and groove binding of an acridine-spermine conjugate on DNA sequences: an FT-Raman and UV-visible absorption study, J. Mol. Struct. 744/747 (2005), 699-704.

[84] W. Ke, D. Yu and J. Wu, Raman spectroscopic study of the influence on herring sperm DNA of heat treatment and ultraviolet radiation, Spectrochim. Acta A 55 (1999), 1081-1090.

[85] A.J. Ruiz-Chica, A.R. Khomutov, M.A. Medina, F. Sánchez-Jiménez and F.J. Ramírez, Interaction of DNA with an aminooxy analogue of spermidine - an FT-IR and FT-Raman approach, J. Mol. Struct. 565/566 (2001), 253-258.

[86] A.J. Ruiz-Chica, M.A. Medina, F. Sánchez-Jiménez and F.J. Ramírez, Raman study of the effects of polyamines on DNA: spermine and histamine, J. Mol. Struct. 480/481 (1999), 455-458.

[87] M.V.P. Chowdary, K.K. Kumar, K. Thakur, A. Anand, J. Kurien, C.M. Krishna and S. Mathew, Discrimination of normal and malignant mucosal tissues of the colon by Raman spectroscopy, Photomed. Laser Surg. 25 (2007), 269-274.

[88] K.U. Schallreuter, C. Krüger, H. Rokos, S. Hasse, C. Zothner and A. Panske, Basic research confirms coexistence of acquired Blaschkolinear Vitiligo and acrofacial Vitiligo, Arch. Dermatol. Res. 299 (2007), 225-230.

[89] G. Bernard, M. Auger, J. Soucy and R. Poliot, Physical characterization of the stratum corneum of an in vitro psoriatic skin model by ATR-FTIR and Raman spectroscopies, Biochim. Biophys. Acta 1770 (2007), 1317-1323.

[90] G. Zhang, D.J. Moore, C.R. Fach and R. Mendelsohn, Vibrational microscopy and imaging of skin: from single cells to intact tissue, Anal. Bioanal. Chem. 387 (2007), 1591-1599.

[91] Y. Ye, J. Hu, L. He and Y. Zeng, Surface-enhanced Raman spectroscopy of some Schiff base complexes and their interaction with DNA, Vibr. Spectrosc. 20 (1999), 1-4.

[92] R. Hage, P.R. Galhanone, R.A. Zângaro, K.C. Rodrigues, M.T.T. Pacheco, A.A. Martin, M.M. Netto, F.A. Soares and I.W. Cunha, Using the laser-induced fluorescence spectroscopy in the differentiation between normal and neoplastic human breast tissue, Lasers Med. Sci. 18 (2003), 171-176.

[93] A.P. Oliveira, A.A. Martin, L. Silveira, Jr., R.A. Zângaro and M. Zampieri, Application of principal components analysis to diagnosis hamster oral carcinogenesis: Raman study, Biomed. Vibr. Spectrosc. 5321 (2004), 111-116.

[94] L.P. Choo-Smith, H.G.M. Edwards, H.P. Endtz, J.M. Kros, F. Heule, H. Barr, J.S. Robinson, H.A. Bruining and G.J. Puppels, Medical applications of Raman spectroscopy: from proof of principle to clinical implementation, Biopolymers $\mathbf{6 7}$ (2002), 1-9. 
[95] X. Gao, I.S. Butler and R. Kremer, A near-infrared Fourier transform Raman spectroscopy of epidermal keratinocytes: changes in the protein-DNA structure following malignant transformation, Spectrochim. Acta A 61 (2005), 27-35.

[96] A. Nijssen, K. Maquelin, L.F. Santos, P.J. Caspers, T.C.B. Schut, J.C. den Hollander, M.H.A. Neumann and G.J. Puppels, Discriminating basal cell carcinoma from perilesional skin using high wave-number Raman spectroscopy, J. Biomed. Opt. 12 (2007), 034004.

[97] F. Zheng, Y. Qin and K. Chen, Sensitivity map of laser tweezers Raman spectroscopy for single-cell analysis of colorectal cancer, J. Biomed. Opt. 12 (2007), 0398011.

[98] P.O. Andrade, R.A. Bitar, K. Yassoyama, H. Martinho, A.M.R. Santo, P.M. Bruno and A.A. Martin, Study of normal colorectal tissue by FT-Raman spectroscopy, Anal. Bioanal. Chem. 387 (2007), 1643-1648.

[99] R.A. Bitar, H.S. Martinho, C.J. Tierra-Criollo, L.N.Z. Ramalho, M. Mourão and A.A. Martin, Biochemical analysis of human breast tissues using Fourier-transform Raman spectroscopy, J. Biomed. Opt. 11 (2006), 054001.

[100] D.C.B. Redd, Z.C. Feng, K.T. Yue and T.S. Gansler, Raman spectroscopic characterization of human breast tissues: implications for breast cancer diagnosis, Appl. Spectrosc. 47 (1993), 787-791.

[101] F.M. Lyng, E.O. Faoláin, J. Conroy, A.D. Meade, P. Knief, B. Duffy, M.B. Hunter, J.M. Byrne, P. Kelehan and H.J. Byrne, Vibrational spectroscopy for cervical cancer pathology, from biochemical analysis to diagnostic tool, Exp. Mol. Pathol. 82 (2007), 121-129.

[102] A.P. Oliveira, R.A. Bitar, L. Silveira Jr., R.A. Zângaro and A.A. Martin, Near-infrared Raman spectroscopy for oral carcinoma diagnosis, Photomed. Laser Surg. 24 (2006), 348-353.

[103] J.T. Motz, S.J. Ghandi, O.R. Scepanovic, A.S. Haka, J.R. Kramer, R.R. Dasari and M.S. Feld, Real-time Raman system for in vivo disease diagnosis, J. Biomed. Opt. 10 (2005), 031113.

[104] S. Koljenovic, T.C.B. Schut, R. Wolthuis, B. de Jong, L. Santos, P.J. Caspers, J.M. Kros and G.J. Puppels, Tissue characterization using high wave number Raman spectroscopy, J. Biomed. Opt. 10 (2005), 031116.

[105] C.J. Lima, M. Simões, L. Silveira, Jr., L. Silveira, A.B. Villaverde and M.T.T. Pacheco, Multifiber optical catheter with bending control of distal end: Applications of Raman biospectroscopy, J. Appl. Spectrosc. 74 (2007), 107-114.

[106] C.J. Lima, S. Sathaiah, M.T.T. Pacheco, R.A. Zângaro and R. Manoharan, Side-viewing fiberoptic catheter for biospectroscopy applications, Lasers Med. Sci. 19 (2004), 15-20.

[107] C.J. Lima, S. Sathaiah, L. Silveira, Jr., R.A. Zângaro and M.T.T. Pacheco, Development of catheters with low fiber background signals for Raman spectroscopy diagnosis applications, Artif. Organs 24 (2000), 231-234.

[108] K. Tanaka, M.T.T. Pacheco, J.F. Brennan, I. Itzkan, A.J. Berger, R.R. Dasari and M.S. Feld, Compound parabolic concentrator probe for efficient light collection in spectroscopy of biological tissue, Appl. Opt. 35 (1996), 758-763.

[109] C.J. Lima, M. Simões, M.T.T. Pacheco, L. Silveira, Jr. and A.B. Villaverde, Optical fiber catheter with distal end bending mechanism control for Raman biospectroscopy, Instrum. Sci. Technol. 36 (2008), 43-55.

[110] N. Stone, R. Backer, K. Rogers, A.W. Parker and P. Matousek, Subsurface probing of calcifications with spatially offset Raman spectroscopy (SORS): future possibilities for the diagnosis of breast cancer, Analyst 132 (2007), 899-905.

[111] O.F. Nascimento, A.B. Villaverde, R.A. Zângaro, M.T.T. Pacheco and S.F. Durrant, Optical fiber device and biological tissue phantoms for determination of optical parameters in the near-infrared region, Instrum. Sci. Technol. 32 (2004), 489-505.

[112] J. Shen, Y. Ye, J. Hu, H. Shen and Z. Le, Surface-enhanced Raman spectra study of metal complexes of $N$-D-glucosamine $\beta$-naphtaldehyde and glycine and their interaction with DNA, Spectrochim. Acta A 57 (2001), 551-559.

[113] J. Olofsson, B. Önfelt, P. Lincoln, B. Nordén, P. Matousek, A.W. Parker and D. Tuite, Picosecond Kerr-gated timeresolved resonance Raman spectroscopy of the $\left[\mathrm{Ru}(\mathrm{phen})_{2} \mathrm{dppz}\right]^{2+}$ interaction with DNA, J. Inorg. Biochem. 91 (2002), $286-297$. 


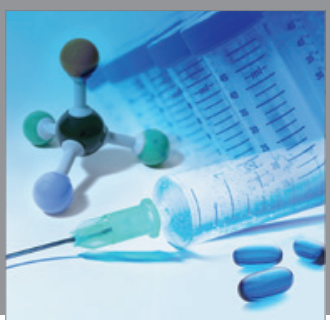

International Journal of

Medicinal Chemistry

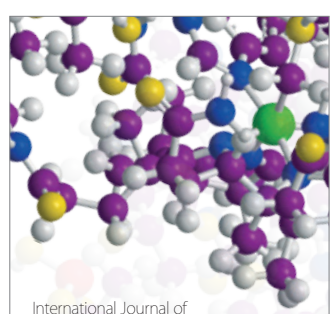

Carbohydrate Chemistry

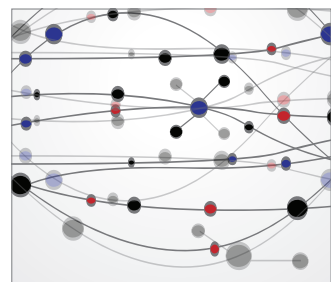

The Scientific World Journal
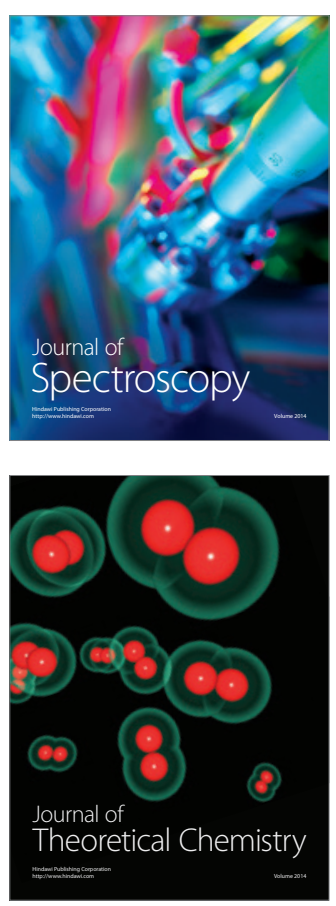
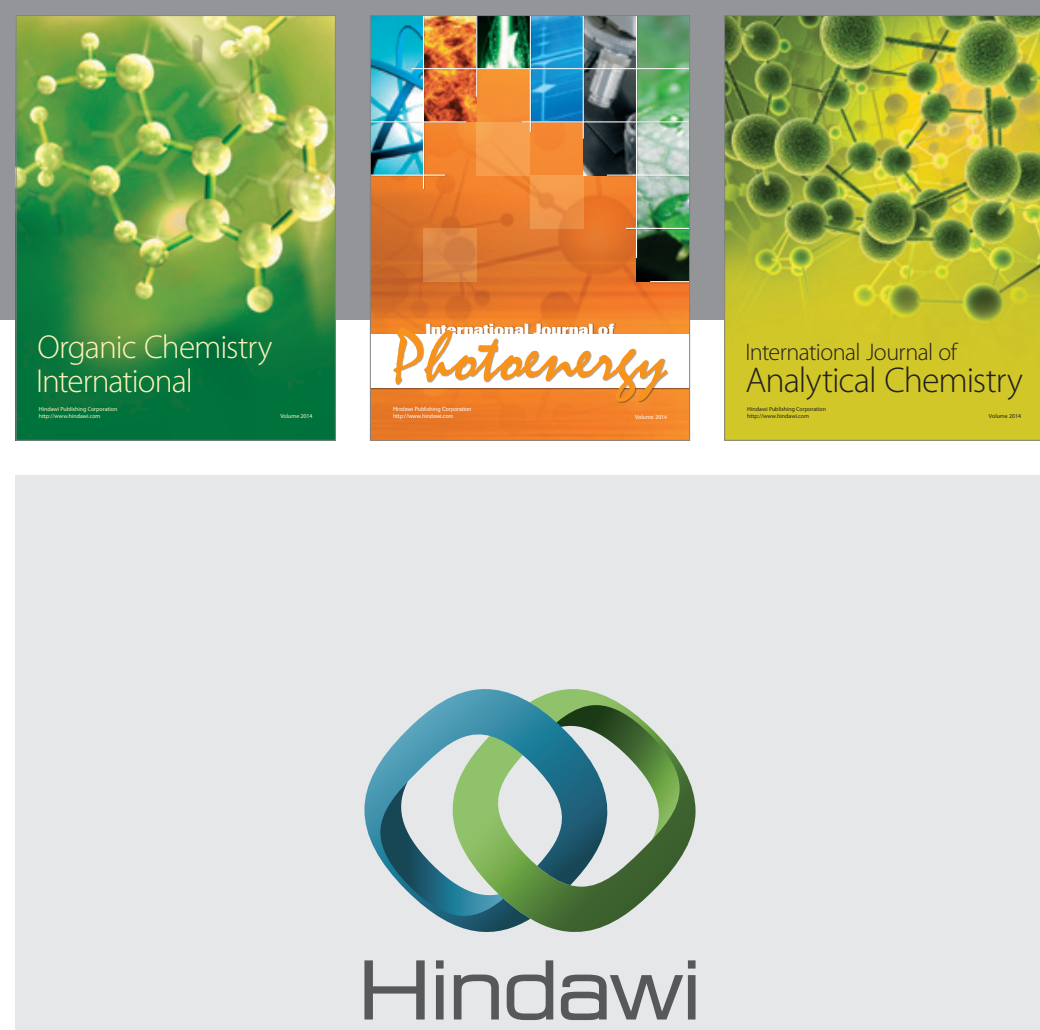

Submit your manuscripts at

http://www.hindawi.com
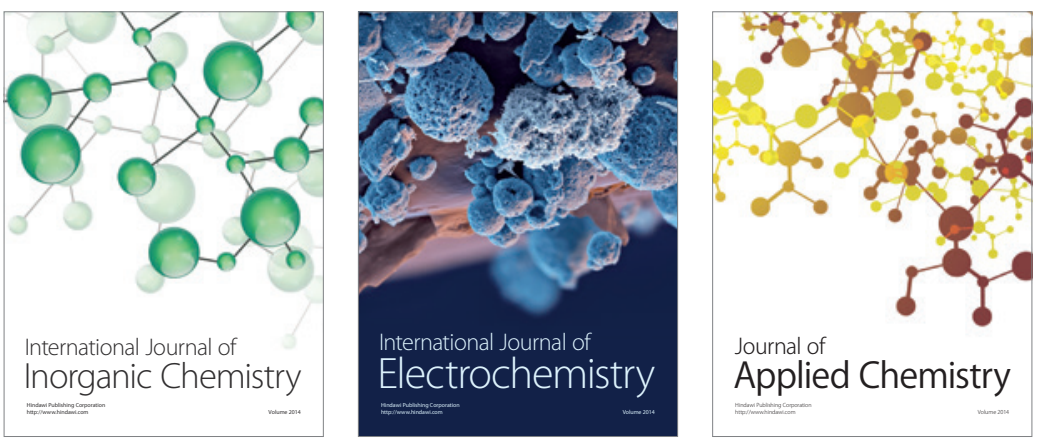

Journal of

Applied Chemistry
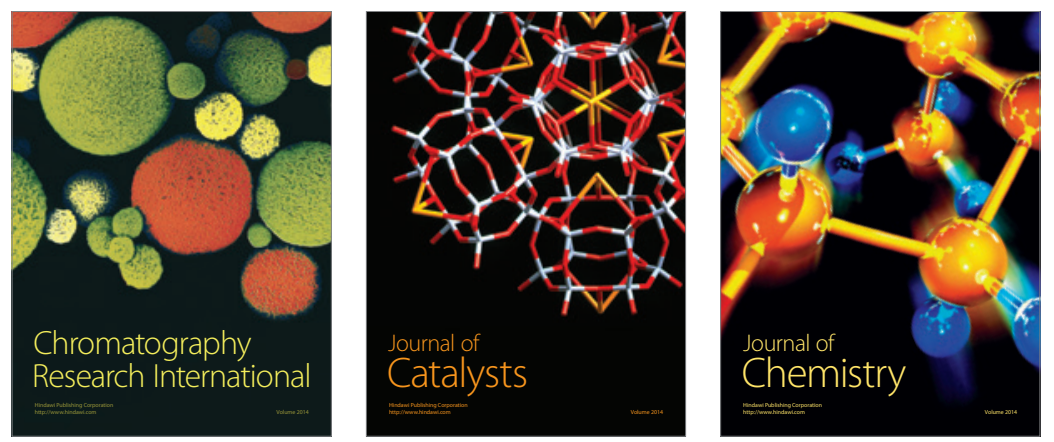
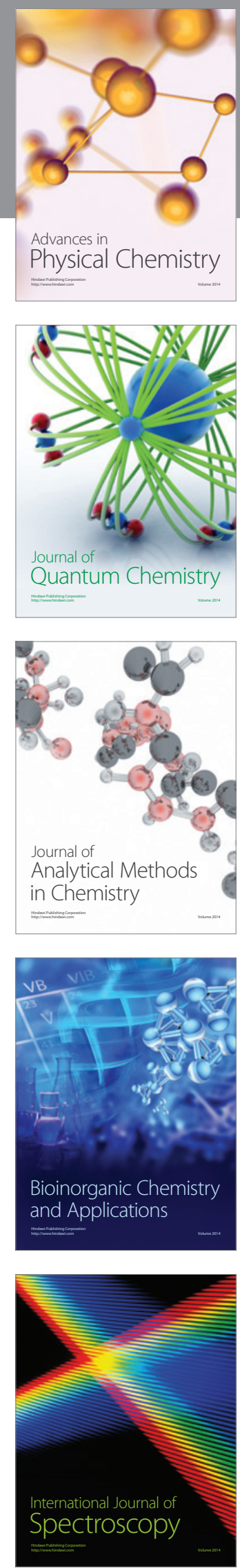